\title{
Doom/gothic metal: comunicação e melancolia através das redes digitais e analógicas
}

\author{
Jeder Janotti \\ Universidade Federal da Bahia
}

O rock é descendente do grito negro dos escravos norte-americanos e da melancolia dos acordes oriundos do blues. A arqueologia do rock é profundamente marcada pela blue note e seu grito existencial, com o heavy metal não poderia ser diferente. "Uma genealogia do heavy metal deveria ser delineada a partir do blues afro-americano, mas isso raramente é feito. Do mesmo modo que as histórias da América do Norte começam com a invasão européia, as histórias dos gêneros musicais como rock e heavy melal normalmente começam no ponto da dominação branca. Mas enfatizar a contribuição do Black Sabbath para o interesse do rock pelo ocultismo é esquecer a batalha entre Robert Johnson com o demônio $\mathrm{e}$ as meditações de Howlin'Wolf a respeito do problema do mal. Investigar o estilo vocal do heavy metal a partir de Robert Plant do Led Zeppelin é esquecer James Brown 'Cold Sweal' "(Walser; 1993, p:8).

Os elementos que criam o feeling em torno da nomenclatura heavy melal; como os vocais guturais, o volume e a distorção são características oriundas do blues de Memphis e Kansas City, cidades que marcaram a urbanização do blues e sua eletrificação. Não por acaso, o heavy metal herda alguns elementos que caracterizaram a angústia e o sofrimento do grito negro por um sopro de liberdade, transformando a música em uma espécie de catarse melancólica. "O Heavy Metal possui uma tendência em abraçar os conflitos ocultos e frustrações da vida que não podem ser resolvidos pelas reformas políticas ou revolução. Essas dificuldades devem ser reconhecidas e superadas individualmente. Pressionando as fronteiras da vida cotidiana e penetrando a desordem e falta de sentido além dessas fronteiras, o heavy metal 
assemelha-se ao movimento filosófico existencialista"( Weinstein 1991:242).

O heavy metal surge em meio a fissura e confusão do início da década de setenta, época marcada pela perda das referências que marcaram o rock durante a década de sessenta, que culminaram nos movimentos de maio de 1968. Se a tomada de consciência e a mobilização provocaram uma mostra do poder de aglutinação da juventude em busca de um espaço societal, a década de setenta vai ser marcada pela angústia de dormir com os anjos e acordar em um pesadelo. Como bem expressou John Lennon : "O sonho acabou! Com isso quero dizer que toda euforia do poder jovem - o mito da nova geração, enfim se foi" (apud Muggiati 1973:75).

A década de setenta é marcada pela fratura, onde o pensamento calcado na utopia se esfacela; seu reflexo no rock pode ser observado na proliferação de diversos estilos musicais e na passagem da utopia para uma espécie de heterotopia, fragmentação característica da Cultura Contemporânea (Cf. Vattimo 1992). São os destroços de 1968, o ideal de uma união hippie é substituído pela profusão de estilos musi-

cais, como art rock, progressive rock e folk rock e é claro o heavy metal.

Apesar da efervescência do rock durante a década de setenta e a retomada de seu vigor contestatório a partir do movimento punk, é só durante a década de oitenta que o heavy metal vai se firmar realmente como um gênero dentro do rock. Bandas como Iron Maiden, Scorpions, $A c / D c$ e Van Halen acabaram dando visibilidade e projetando o espaço de vivência dos fãs de heavy metal para além da idéia de um gênero musical. Através dos trajes, dos shows e dos locais de encontro; os fãs de heavy metal construíram territórios existenciais, onde é possível exercitar a subjetividade fora dos espaços normatizados. Esse 'neotribalismo' enseja a idéia de um imaginário metálico como forma de agregação social característica da Cultura Contemporânea. "A sociabilidade marcaria ('daria o tom') os agrupamentos urbanos contemporâneos, colocando ênfase na 'tragédia do presente', no instante vivido além de projeções futuristas ou morais, nas relações banais do cotidiano, nos momentos não institucionais, racionais ou finalistas da vida de todo dia. Isso a diferencia da sociabilidade que se caracteriza por relações institucionalizadas e formais de uma determinada sociedade" (Lemos, 1998:2).

$\mathrm{Na}$ década de oitenta o sistema de comunicação broadcasting acabou assimilando a nova safra de grupos denominados heavy metal, 
ampliando os horizontes mercadológicos e dando visibilidade ao gênero. Mas, ao fazer isso, as bandas deixaram de caracterizar as particularidades da "tribo metálica" e ameaçavam os aspectos particularistas que demarcavam o espaço tribal. É nesse cenário que tem início o fenômeno das divisões do heavy em vários subgêneros; valorizando as formas comunicacionais dos meios ditos "alternativos" como as gravadoras especializadas e o retorno dos fanzines, que haviam sido uma das formas básicas de difusão do movimento hippie, do movimento punk e do heavy metal do inicio dos anos oitenta. "A expansão dos subgêneros do heavy metal torna-se parte de um largo complexo cultural (...) A nova formação, chamada aqui 'metal', inclui ambos heavy metal e subgêneros próprios, cada um desses membros sendo definidos através de códigos distintos que contém alguns ou todos os elementos do código heavy metal"(Weinstein 1991:55).

Na década de noventa o heavy metal deixa de possuir a visibilidade da década anterior e acaba retornando a uma espécie de "underground". A sonoridade pesada já não é mais uma exclusividade do metal, tendo em vista que, quando o movimento grunge atinge a midia broadcasting, essa marca distintiva é rapidamente assimilada por outros gêneros musicais; e bandas da década de oitenta como Van Halen, Scorpions e Deff Lepard acabam deixando de lado os elementos típicos do heavy metal. A crítica norte-americana chega a declarar o fim do gênero "metálico" (Cf. Rock Brigade, ano 16, n 133).

O certo é que, apesar do gênero não possuir mais a visibilidade da década de oitenta, ele acaba valorizando ainda mais seus aspectos tribais. A Europa, em especial os paises nórdicos, será responsável pela manutenção e pelo "espraiamento" de diversos subgêneros do heavy metal como o heavy metal melódico, o black metal, o progmetal, o death metal e o doom/gothic metal. A manutenção do heavy metal na Europa, na América Latina, em Israel e no Japão acaba corroborando uma das principais características da Comunicação e Cultura Contemporâneas: ao lado da globalização dos grandes conglomerados midiáticos é possivel perceber a convivência (mesmo que tensiva) de mídias alternativas, grupos específicos, produções de sentido localizadas e uma enorme interação entre aspectos mundiais e regionalizados.

É diante desse quadro que o presente trabalho pretende abordar o subgênero denominado doom/gothic metal, "originalmente, doom metal era uma filosofia legítima $\{$ sic $\}$ baseada nos sentimentos de desesperança surgido das experiências juvenis da área industrial de 
Birmingham (cidade onde surgiu o Black Sabbath)". Isto envolve os restos da era hippie em termos de influência espiritual, desafios sonoros, usos e abusos das drogas (em alguns casos testamentos do que elas poderiam fazer com a imaginação) e sons ultrapessimistas sobre a guerra . Hoje a filosofia central não mudou muito. Ela ainda é voltada aos sentimentos de desesperança individual. Entretanto, grande parte das letras produzidas agora são centradas em temas individuais, problemas em micro-escalas como amor, tristeza, privações, perda da fé, etc.(...) Línguas estrangeiras como latim, espanhol, francês, escandinavo e japonês são comuns no doom metal (...) E seus álbuns soam lentos e dolorosos "(Cf. http://members.xoom.com./doomguide/ faq.htm).

Abrindo espaços que possibilitem essa vivência nostálgica (tanto do mito do paraíso perdido como do eterno sentimento de "incompletude") que caracteriza a experiência humana, o doom metal acaba trabalhando elementos contrapostos à extrema rapidez dos fluxos temporais da Cultura Contemporânea, explicitados pelo mosaico do zappening televisivo ou pela instantaneidade do fluxo da internet. bandas como Paradise Lost, Saturnus, My Dying Bride, Moonspell, The Gathering, Theatre of Tragedy e Anathema acabam reclamando um espaço societal que valorize uma vivência simbólica, uma partiIha de sentimentos que reforce a melancolia característica da vivência dolorosa da passagem do tempo, dos dejetos produzidos pela produtividade excessiva e da desvalorização da nostalgia e da consciência de nossa mortalidade como elementos essencialmente humanos. Mesmo que, por mais paradoxal que possa ser, esse feeling seja canalizado através das redes infográficas e das inúmeras possibilidades de vivências abertas pela internet (cf. http://www.geocities.com/ SunsetStrip/Lounge/3994/geobook.html//http://www.brunel.ac.uk/ 〜mapgpam/anathema/lyrics.htmlhttp://www.truemetal.org/gallows/ll http://www.lut.fi/ mega/muzac/doomlist.html). A utilização da Rede neste caso acaba sendo uma característica fundamental, pois se tornou uma das principais formas de comunicação mediática do heavy metal e seus diversos subgêneros, já que os webzines e as homepages acabam cumprindo com sucesso os requisitos ligados aos ideais de independência, especificidade, facilidade de produção e eficácia comunicacional associadas tradicionalmente aos fanzines. Colocar na rede o ritmo lento e nostálgico do doom/gothic metal associado ao próprio dezenraizamento oriundo dessa experiência comunicacional é valorizar o sentimento da perda como uma das formas de sensibilida- 
de possíveis no universo da cibercultura. "A melancolia é uma estratégia de aprendizado e sobrevivência do sujeito em meio a dispersão" (Lopes 1997: 10).

A relação entre o doom metal e a internet não significa que ele se caracteriza especificamente como uma forma de socialidade centrada no universo da navegação informática, mas que como subgênero centrado em uma sensibilidade marginal em relação aos grandes conglomerados multimidiáticos, ou seja, que depende das chamadas gravadoras e meios informacionais 'alternativos' ou 'independentes', a tribo dos fãs de doom/gothic metal passa pela internet, mas não é totalmente dependente do ciberespaço. Essa ligação acaba valorizando a idéia de passagens (Cf. Bellour 1993) como uma das características de algumas expressões culturais da contemporaneidade deste modo o doom/gothic metal valoriza uma experiência comunicacional fundada nos cruzamentos entre territórios virtuais, simbólicos e fisicos. Navegar na internet não significa abrir mão dos shows, dos contatos corporais e de objetos como discos e camisetas. A própria idéia de circulação, e conseqüentemente de transitoriedade, levanta questões ligadas ao espaço comunicacional. A espacialidade é "experienciada" a partir da tensão entre um mundo que se expande e ao mesmo tempo diminui. Esta tensão não pode ser esquecida quando abordamos os atalhos e declives da comunicação contemporânea. Circular desenfreadamente é abrir-se ao movimento pelo movimento, obliterando as paradas e prescindindo de qualquer ponto de chegada, paradoxo de que circular pode representar paralisia, um sentimento propicio a sensibilidades nostálgicas e melancólicas. "Destacar-se então de um falso nomadismo que na verdade nos deixa no mesmo lugar, no vazio de uma modernidade exangue, para aceder às verdadeiras errâncias do desejo, às quais as desterritorializações técnico-cientificas, urbanas, estéticas, maquínicas de todas as formas nos incitam"( Guatarri, 1992:190).

Como elemento de um gênero musical, o doom/gothic metal tem como uma das formas primordiais de 'cimento societal' primeiramente a música: que é extremamente lenta, angustiante e muitas vezes utiliza elementos estranhos ao heavy metal tradicional como vocais femininos, cordas e letras que tratam em muitos casos de uma certa "melancolia existencial". A sonoridade funda neste caso uma estética tribal, entendendo estética no sentido empregado por Michel Maffesoli, ou seja, como modo de experimentar, de sentir comum, tornando-se um modo de reconhecimento calcado na música, no espa- 
ço simbólico e no feeling melancólico.

A sonoridade gótica (entendida aqui como obscura, opressiva e lenta; utilizando recursos como cordas, teclados e vocais femininos) do doom e o ritmo extremamente lento da maioria de suas músicas acabam abrindo possibilidade de uma vivência centrada na angústia e na melancolia, elementos "saturnianos" que corroboram a extrema fragmentação da Cultura Contemporânea.. Deste modo, o gothic/ doom metal abre espaço para a experiência do luto, da morte e da angústia como espaços simbólicos fundamentais, pois, “(...) há luto sempre: não que nenhum de nossos desejos jamais seja satisfeito, não somos infelizes a esse ponto, mas porque jamais o poderiam ser todos, nem definitivamente"(Comte-Sponville 1997:89). Afinal, as experiências da dor, da morte e da perda são cruéis não só por serem trágicas, mas porque revelam aspectos do indizível, sentimentos que podem ser traídos, descritos, mas não podem ser comunicados em sua totalidade, pois são únicos, intransferíveis. Quando o doom/gothic procura trabalhar esse "feeling", que em geral é negligenciado pelos produtos midiáticos broadcasting, acaba abrindo espaços onde é possível experimentar uma socialidade calcada na vivência de nossos próprios limites. "Assim o homem é a única criatura conhecida a ter consciência de sua própria morte (como da morte destinada a toda coisa), mas também a única a rejeitar inapelavelmente a idéia de morte"(Rosset, 1989:22). Deste modo é possível perceber que espaços de vivências simbólicas e experiências societais como a internet e a sonoridade "metálica" do doom/gothic metal acabam formando uma dobra, uma espécie de interface, que faz emergir feelings ligados aos aspectos de uma experiência comunicacional tradicional que valoriza elementos fundamentais da finitude da existência humana e ao mesmo tempo utiliza as novas tecnologias e o processo de mundialização das redes telemáticas como um meio de divulgação, e conseqüentemente de vivência tribal, dessa forma de produzir sentido na Cultura Contemporânea, ou seja, é uma manifestação híbrida, situada entre encontros localizados em espaços tradicionais e o espaço virtual. Aqui podemos enxergar mais uma das características fundamentais da cultura hodierna, no entrecruzamento, um espaço entre-imagens. Como afirma Suely Rolnik: "Essa aliança depende - mais do que qualquer outro tipo de aprendizado- de estar à escuta do mal-estar mobilizado pela desestabilização em nós mesmos, da capacidade de suportá-lo e de improvisar formas que dêem sentido e valor àquilo que essa incômoda sensação nos sopra"( Rolnik in Lins 1997:32). 
O doom/gothic metal está situado além da nomeação subgênero musical, ele é antes de tudo a expressão de um determinado modo de 'simbolizar' certos elementos que em geral são obliterados em nosso cotidiano, como afirma a banda Paradise Lost em uma de suas letras: "Another day won't ease the sorrow/another day will help frustration to grow all the pictures and the face of hope/I have taken warning when the day is just begun"*

O doom/gothic surgiu junto com a proliferação da internet, a experiência comunicacional ( Cf. Rodrigues 1994) está vinculada à navegação na rede, mas a internet funciona como um dos acessórios que permitem a construção desta experiência e não como fator determinante; suas expressões simbólicas envolvem todo o campo imagético calcado no sombrio (ai podemos perceber a própria nomenclatura gótica), posturas melancólicas através de ligações com a poesia de John Milton, William Blake e Fernando Pessoa, entre outros; elementos que fundam a socialidade tribal, ou seja, contribuem para situar a persona dentro da tribo. Aqui as experiências da dor, da incompletude e da angústia existencial humana serão objetos de estudo a partir das expressões simbólicas destes sentimentos. Os simbolos, seja através do imaginário veiculado na sonoridade, nas letras ou nas imagens (via rede, videografia ou capas de disco) funcionam como elementos de um sentir comum fundador do cimento societal desta tribo.

A interação entre elementos oriundos de uma experiência eminentemente trágica, centrada em um tempo mítico (mortalidade, dor e existência) com elementos da cibercultura (dinamismo, velocidade e fragmentação) acaba sendo um elemento fundamental na busca de estudos que visem analisar as possibilidades de compreensão e experiências comunicacionais na Cultura Contemporânea. O doom/gothic metal acentua um problema crucial para os estudiosos dos processos comunicacionais hodiernos: a inter-relação entre os ritos contemporâneos, sua mitologia particularizada e suas relações com mitos arquetípicos que evidenciam sensibilidades ligadas à idéia de perda do paraiso, a angústia existencial e a idéia de perenidade. "As diversas manifestações contemporâneas da cibercultura podem ser vistas como a expressão quotidiana dessa vida 'tecnicizada' que se rebela contra as formas instituídas e cristalizadas (lembremos que o ciberespaço é fruto de pesquisas militares). A forma técnica molda-se ao conteúdo social, não sem conflitos"(Lemos 1998:10). 
É na partilha da comunicação proporcionada pela internet, suas especificidades e socialidades próprias, e pelos meios 'tradicionais' de comunicação tribal como a sonoridade e a visualidade que podemos discernir 'segredos e rituais' que pontuam o universo tribal do doom/gothic metal. É na vivência deste espaço simbólico que o grupo busca uma experiência comunicacional permeada pelo imaginário melancólico. A diferença em relação ao universo social globalizante é que o grupo estabelece uma paridade entre seus membros, fundando uma espécie de constelação de sentido. Tal aspecto na relação grupal é fundamental, porque implica uma abordagem da dinâmica societal centrada na análise simbólica, no entrecruzamento dos espaços virtuais/locais e do imaginário tribal.

A análise da socialidade e da sensibilidade do gothic/doom metal visa compreender uma das possibilidades de produção de sentido abertas através dos cruzamentos entre o espaço imagético, a sensibilidade melancólica, a sonoridade e suas representações via internet. Isto remete ao reconhecimento dessa forma específica de agrupamento como um espaço simbólico, que possibilita a partilha de uma experiência comunicacional específica, possibilitando a vivência de sensibilidades como a angústia e a melancolia na inter-relação entre sentimentos que pontuam a existência humana de uma maneira geral, mas que podem ser vivenciados de maneiras características, utilizando mitos arquetípicos a partir de elementos eminentemente contemporâneos, como na propagação desta sensibilidade pela internet(Cf.http:/ /www.borg.com/ lordxul/tears.htm//http://www.rz.unifrankfurt.de/ $\sim$ fxmts205/Music/Tiamat/http://www.highlightech.com/users/kiki/ inside.html-ssi). Como afirmou o filósofo Félix Guatarri: "O rock desempenha uma pseudo-identidade cultural a massas consideráveis de jovens, permitindo-lhes construir um mínimo de territórios existências"(1990:14).

A compreensão das manifestações simbólicas e comunicacionais do doom/gothic metal procura evidenciar uma das formas de socialidade que trabalha elementos que normalmente não fazem parte do universo tradicional da sensibilidade pop, em geral, centrada em aspectos dionisíacos. Ao assumir uma socialidade baseada em sensibilidades 'saturninas' o doom/gothic metal procurar trabalhar subjetividades que normalmente não fazem parte das narrativas tradicionais dos meios broadcasting; isso corrobora a idéia de que uma sociedade fragmentada/segmentada, apesar de possuir uma série de discursos hegemônicos, acaba por possibilitar, através da comunicação em mo- 
saico, a emergência de espaços simbólicos que permitem a formação de subjetividades alternativas aos padrões estabelecidos, sendo que estas sensibilidades fazem parte de uma espécie de contrafluxo do sentimento hegemônico propagado pela Cultura Contemporânea.. Ao buscar formas de "vivenciar" a dinâmica das redes, a cadeia de distribuição musical e a produção de sentido tradicionalmente ligada ao rock, este subgênero do heavy metal procura lembrar processos presentes nos mitos ligados ao luto e à idéia do paraíso perdido, ou seja, que "(...) nascemos na angústia, morremos na angústia. Entre os dois, o medo quase não nos deixa. O que mais angustiante do que viver? É que a morte é sempre possível, o sofrimento é sempre possivel, e é isso que se chama um vivente: um pouco de carne oferecida à agressão do real "(Comte-Sponville 1997:11).

É na tensão entre aquilo que é partilhado, o campo teórico e as possibilidades expressadas nos fenômenos de partilha de sentido que podemos procurar compreender a experiência comunicacional. Compreender é procurar delimitar as possibilidades comunicativas, mas também assumir que algo se perdeu, que arbitrariamente interrompemos o fluxo de sentido. A incompreensibilidade é elemento constitutivo do devir comunicativo. Comunicar também deve ser assumir a imponderabilidade do processo comunicativo. O que na ótica aqui apresentada só reforça a necessidade de procurar analisar um tribalismo contemporâneo que é calcado em uma sociabilidade melancólica, que parece assumir a fratura e a incompletude como elementos constituintes da idéia do devir que caracterizaria a idéia da existência humana (Cf. http://www.geocities.com/Paris/Cafe/5775/ death.html).

Analisar os aspectos ligados a uma representação particular do universo tribal contemporâneo é valorizar os estudos pontuais e suas manifestações cotidianas como um dos campos de estudo fundamentais para entender a complexa teia agrupada sob o nome de Cultura Contemporânea. A cartografia do doom/gothic metal é fundada antes de tudo nas fraturas e interstícios encontradas em um movimento que utiliza os canais tradicionais de comunicação como o show, os encontros fortuitos do cotidiano, as fitas de vídeo, o vestuário e a sonoridade; perpassados pela internet e suas particularidades, como a fundação de um estatuto diferenciado na relação entre emissor/receptor, a existência de encontros/comunidades virtuais e uma transformação dos aspectos temporais/espaciais através da circulação/armazenamento de informações. Portanto, um estudo como o aqui apresentado, é uma 
tentativa de compreensão da socialidade contemporânea e seus problemas comunicacionais a partir da inter-relação entre a experiência comunicacional em seus aspectos tradicionais e sua correlação com as novas tecnologias da informação e comunicação.

\section{Referências Bibliográficas}

BAUMAN, Zygmunt. O Mal-estar da Pós-modernidade. Rio de Janeiro, Jorge Zahar Editor, 1998.

CALABRESE, Omar. A Idade Neobarroca. Lisboa, Edições 70, 1988.

CAMPBELL, Joseph. O Poder do Mito. São Paulo, Pala Athena, 1990.

CANEVACCI, Máximo. Sincretismos, uma Exploração das Hibridações Culturais. São Paulo, Studio Nobel, 1996.

CERTEAU, Michel de A Invenção do Cotidiano. Petrópolis, Vozes, 100 1994. . A Cultura no Plural. Campinas, Papirus, 1997.

CIORAN, E.M. História e Utopia. Rio de Janeiro, Rocco, 1994.

COMTE-SPONVILLE. André. Bom Dia Angústia. São Paulo, Martins Fontes, 1997.

DURAN, Gilbert. As Estruturas Antropológicas do Imaginário. Lisboa, Editorial Presença, 1989.

ECO, Umberto. Sobre os espelhos. Rio de Janeiro, Nova Fronteira, 1989.

GUATARRI, Félix. Caosmose um Novo paradigma Estético. Rio de Janeiro, Editora 34, 1992

HARRIGAN \& DOME. Encyclopedia Metallica. London, Omnibus Press, s.d.

HERZHAFT, Gérard. Blues. Campinas, Papirus, 1989.

JANOTTI JR, Jeder. A Experiência Simbólica, Algumas Anotações a Partir da Obra de C.G.Jung, São Paulo, V Compós, (mimeo).

. Heavy Metal: O Universo Tribal e o Espaço dos Sonhos. Campinas, Unicamp, Departamento de Multimeios, (mimeo dissertação de mestrado), 1994. 
.666 The Number of The Beast: Alguns Apontamentos Sobre a Experiência Simbólica a Partir das Letras, Crânios, Demônios e Sonhos do Heavy Metal. Porto Alegre, VI Compós, 1997 (mimeo).

JUNG, Carl Gustav. Fundamentos da Psicologia Analitica. Petrópolis, Vozes, 1987. . Psicologia e Alquimia. Petrópolis, vozes, 1991. . Simbolos da Transformação. Vozes, 1986.

LEÃO, Tom. Heavy Metal. Rio de Janeiro, Editora 34, 1998.

KAPLAN, E. Ann. O Mal-estar no Pós-modernismo - Teorias e Práticas. Rio de Janeiro, Jorge Zahar, 1993.

LEMOS, André. Ciber-socialidade - Tecnologia e Vida Social na Cultura Contemporânea. São Paulo, VII Compós, 1988, (mimeo).

LÉVY, Pierre. As Tecnologias da Inteligência. Rio de Janeiro, Editora 34, 1993.

LINS, Daniel (org.). Cultura e Subjetividade: Saberes Nômades. Campinas, Papirus, 1997.

LOPES, Denílson. Nós os Mortos (Sensibilidades Melancólicas, Imagens Neo-Barrocas). Brasília - UNB (Departamento de Sociologia), 1997 (mimeo - Tese de Doutorado).

MAFFESOLI, Michel. A Contemplação do Mundo. Porto Alegre, Artes e Oficios, 1995.

- A Conquista do Presente. São Paulo, Rocco, 1984.

. Dinâmica da Violência. São Paulo, Edições Vértice, 1987.

1987.

. O Tempo das Tribos. Rio de Janeiro, Forense Universitária,

MUGGIATI, Roberto. O Grito e o Mito. Petrópolis, Editora Vozes, 1983. 1983.

História do Rock (4volumes). São Paulo, Editora Três,

ORTIZ, Renato. Mundialização e Cultura. São Paulo, Editora Brasiliense, 1994.

PEREZ, Urânia Tourinho (org.). Melancolia. São Paulo, Escuta, 1996.

Rock Brigade. São Paulo, Editora Rock Brigade, 1993/1994/1995/ 1996/1997. 
RODRIGUEZ, Adriano Duarte. Comunicação e Cultura - A Experiência Cultural na Era da Informação. Lisboa, Editorial Presença, 1994.

ROSSET, Clément. O Princípio da Crueldade. Rio de Janeiro, Rocco, 1989.

. O Real e seu Duplo. Rio de Janeiro, Rocco, 1988.

SERRES, Michel. Filosofia Mestiça. Rio de Janeiro, Nova Fronteira, 1993.

WALSER, Robert. Power, Gender, and madness in Heavy Metal Music. Hanover/London,

Wesleyan University Press, University Press of New England, 1993.

WEINSTEIN, Deena. Heavy Metal: A Cultural Sociology. New York, Lexington Books, 1991.

\section{Notas}

1021 O autor é professor do Departamento de Comunicação da Facom/ Univ. Federal da Bahia, Mestre em Multimeios (Unicamp) e doutorando do Programa de Pós-Graduação em Ciências da Comunicação da Univ. do Vale do Rio do Sinos (RS).

2 A afirmação entre parênteses é de minha autoria, já que o autor da homepage pressupõe que os leitores possuam conhecimento prévio deste fato.

3 Another Day, música do disco One Second, Music For Nations 1997. 